\title{
AGE DIFFERENCES IN TYPES OF INTERPERSONAL TENSIONS*
}

\section{KELLY E. CICHY}

Pennsylvania State University

KAREN L. FINGERMAN

Purdue University

EVA S. LEFKOWITZ

Pennsylvania State University

\begin{abstract}
This study examined age differences in topics that generate interpersonal tensions as well as relationship level characteristics that may account for variability in the content of interpersonal tensions. Participants aged 13 to 99 years $(N=184)$ diagramed their close and problematic social networks, and then provided open-ended descriptions of recent tensions with up to 6 social partners. Multilevel models were conducted to examine variability in 5 types of tensions (i.e., financial issues, daily activities, scheduling, job/school, and self). Older adults were less likely than younger ages to describe tensions over job/school and daily activities. Job/school tensions were more likely to occur with acquaintances and negative network members. Tensions over scheduling were more likely to occur with positive and ambivalent network members, and tensions over daily activities were associated with less emotional distress. Results suggest relationship characteristics contribute to the content of tensions.
\end{abstract}

*This study was supported by grant R03 "Adults' Reasoning About Problems in Social Relationships" and grant R01AG17916 "Problems Between Parents and Offspring in Adulthood" from the National Institute of Aging. The first author was also supported by grant 5 T32 MH018904, from the National Institute of Mental Health, "Research Training in Mental Health and Aging." 
Throughout life, interpersonal tensions are among the most upsetting stressful experiences (Bolger, DeLongis, Kessler, \& Schilling, 1989). Prior research reveals age differences in experiencing these negative interactions. Older individuals tend to report fewer problems with members of their social networks compared to younger individuals (Akiyama, Antonucci, Takahashi, \& Langfahl, 2003; Fingerman \& Birditt, 2003). Older adults also appear more adept at regulating their negative emotions and their behavioral reactions to interpersonal tensions (Birditt, Fingerman, \& Almeida, 2005; Carstensen, Issacowitz, \& Charles, 1999).

Still, older adults are not immune to negative interactions and they do experience tensions with their social partners. When older adults experience tensions, it is unclear whether they are experiencing similar or different types of tensions than those experienced by younger individuals. Theoretically, age differences may characterize the types of tensions individuals describe with their social partners.

Interpersonal tensions include verbal disagreements as well as tense interactions with social partners (Almeida \& Horn, 2004) and represent the most common type of daily stressful experience (Almeida, Wethington, \& Kessler, 2002). Tensions may include disagreements over finances, the division of household labor, driving styles, job procedures, child discipline, or simply feeling disrespected (Almeida et al., 2002). Previous research has explored age variations in the types of tensions individuals experience in the context of a single relationship, such as tensions between parents and offspring (Clarke, Preston, Raksin, \& Bengston, 1999; Fingerman, 1996; Galambos \& Almeida, 1992), between friends (Blieszner \& Adams, 1998; Raffaelli, 1997), or between marital partners (Levenson, Carstensen, \& Gottman, 1993). Less research has examined age variability in the content of tensions across a range of social relationships.

The present study expands upon prior studies of negative interactions by exploring age variability in the content of tensions individuals experienced with their closest and most problematic social partners during the last year. This approach adds to the burgeoning literature on positive and negative social partners (e.g., Akiyama et al., 2003; Fingerman, Hay, \& Birditt, 2004; Rook, 2003) by considering the issues that underlie those tensions. Older adults describe fewer tensions overall (Akiyama et al., 2003), yet it remains unclear whether younger individuals experience more tensions distributed across a diverse range of topics, or whether younger individuals experience more tensions than older adults in some areas of life, but not in others.

This study examines age variability in the types of tensions individuals describe in six content areas: financial issues, daily activities, scheduling, job/school, family, and self, adapted from research exploring variability in the appraisal of interpersonal tensions (Serido, 2003). Financial issues refer to tensions over money or material goods. Daily activities include issues over responsibilities or activities, whereas tensions over time use or missed plans are classified as 
scheduling. Issues over employment or education are classified under job/school, and family encompasses tensions over family responsibilities such as rearing children or grandchildren. Finally, self includes tensions over personal issues or interaction styles.

\section{Age Differences in Exposure to Types of Tensions}

Adults of different ages may report different types of tensions with their social partners. Age-related changes in social roles may limit the number of settings in which older adults interact with social partners and their chances to encounter some types of tensions, but not others. For example, due to age structures of the modern work world, individuals generally engage in paid employment from their early 20s through mid 60s (Riley \& Loscocco, 1994). Similarly, in early and middle adulthood, many individuals are actively engaged in the parental role and responsible for juggling multiple responsibilities (Herzog, Kahn, Morgan, Jackson, \& Antonucci, 1989; Michelson, 1990). These diverse responsibilities may heighten individuals' opportunities to argue with others over disruptions in the timing of events. In comparison, retired older individuals are less likely to engage in active child rearing or paid labor, and have fewer conflicting demands and greater discretion in how they use their time (Altergott, 1990; Horgas, Wilms, \& Baltes, 1998; Ross, 1990).

In contrast, other types of tensions may be characterized by greater age similarity than dissimilarity. Previous studies of negative social interactions suggest that although older adults report fewer tensions than younger individuals, older individuals continue to report tensions with those with whom they have frequent contact, such as their spouses (Akiyama et al., 2003; Almeida \& Horn, 2004). Marital research reveals that division of labor and financial matters remain sources of tension for spouses in both the early and later stages of marriage (Levenson et al., 1993; Suitor, 1991; Wilkie, Ferree, \& Ratcliff, 1998).

In addition, disagreements involving the nature of social interactions may arise in a variety of social contexts. Unlike arguments over jobs or education that may primarily occur in workplaces or schools, tensions involving the self, such as feeling disrespected, could occur in almost any environment. Age-related reductions in the contexts where individuals encounter social partners and experience tensions may have little influence on the likelihood of experiencing tensions over personal issues or social interactions.

In summary, age variability is expected in the content of interpersonal tensions. Specifically, we hypothesized that older adults would be less likely to describe tensions over job/school and scheduling than younger individuals. In comparison, older adults and younger individuals would be equally like to describe other types of tension (i.e. financial issues, daily activities, family, and self; Hypothesis 1). 


\section{Type of Tension as a Function of Relationship Factors and Feelings about the Tension}

The likelihood of experiencing certain types of tensions may also be associated with characteristics of the relationship and feelings about the tension. Prior studies suggest relationship factors, such as type of social partner, frequency of contact, and intensity of distress are associated with negative social experiences (Akiyama et al., 2003; Birditt \& Fingerman, 2003). Specifically, this study examines whether relationship factors, including type of social partner and network membership, and feelings about the tension, including intensity and duration of distress and importance of the tension are associated with variability in types of tensions. Although we may expect these relationship factors and feelings about the tension to be associated with one another it is not clear from the literature how these relationship characteristics and feelings about the tension might influence one another. Due to the exploratory nature of the present study, we separately examine associations between each relationship factor, each feeling about the tension, and the likelihood of experiencing each type of tension. Further, we are interested in determining the extent to which these relationship factors and feelings about the tension are associated with the likelihood of describing different types of tensions after individual characteristics, such as age, are considered.

Prior studies suggest individuals interact in diverse contexts where they encounter different types of social partners (Antonucci \& Akiyama, 1987; Fingerman \& Birditt, 2003; Troll, 1988) and individuals often experience tensions with social partners when they report having frequent contact with them (Akiyama et al., 2003). These findings imply that people experience more tensions within certain contexts with some relationship partners. Similarly, individuals are also likely to experience certain types of tensions with specific social partners. In some contexts, such as the school or workplace, individuals may be more likely to encounter acquaintances, such as classmates or co-workers, who provoke tensions involving job/school. Other types of tensions, such as financial issues, daily activities, scheduling, family, or self may be more likely to arise in the home, where individuals interact with family members or friends. It is hypothesized that individuals of all ages will be more likely to describe tensions involving financial issues, daily activities, scheduling, family, and self with family members and friends, whereas individuals of all ages will be more likely to describe tensions over job/school with acquaintances (Hypothesis 2).

Another characteristic of the relationship, namely the extent to which a network member is characterized as close or problematic may also contribute to the likelihood of experiencing various types of tensions. In this study, as elsewhere (Fingerman et al., 2004; Uchino, Holt-Lunstad, Uno, \& Flinders, 2001), we classified relationships as solely close, solely negative, or mixed and ambivalent (that is both close and problematic). Researchers have distinguished between these three types of relationships to better understand the emotional qualities and impact 
of relationships on individual well-being (Uchino et al., 2001). Further, it appears that negative reactions may vary across different types of social partners. For example, individuals are more likely to consider certain types of social partners, such as spouses and children, as ambivalent, whereas they are more likely to view other types of relationships, such as acquaintances, as solely problematic. Although the literature does not support specific hypotheses, we examined whether solely negative, ambivalent, and solely positive relationships engender different types of tensions (Research Question 1).

Research also indicates attributes of a situation are associated with how individuals appraise and emotionally respond to a situation (Serido, 2003). For this reason, certain types of tensions may be associated with greater and longer lasting emotional distress than other types of tensions. Research suggests that when individuals appraise a situation as more stressful, there is often something of personal value at stake (Almeida et al., 2002; Lazarus, 1999). Tensions involving financial issues may often occur in the context of losing money or being in danger of losing something valuable. Similarly, tensions over job/school, family, and self could result in a loss of self-concept or danger of losing position or a valued relationship. In the event that the tension endangers something of value, such as a financial interest or one's self image, the tension may be associated with a more intense emotional reaction compared to situations where the tension involves less risk. Therefore, we hypothesized that tensions involving financial issues, job/school, family, and self would be associated with more intense, longer lasting emotional distress than tensions over scheduling or daily activities (Hypothesis 3).

Finally, individuals may consider some types of tensions to be important, whereas other types of tensions may be considered more trivial. Just as tensions involving financial issues, job/school, family, and self may be associated with more intense emotional reactions, tensions of these types may be associated with greater importance than tensions over scheduling or daily activities. Although the literature does not provide much information about how different types of tensions vary in importance, we speculated that individuals would consider tensions involving financial issues, job/school, family, and self to be more important than tensions involving scheduling or daily activities (Hypothesis 4).

\section{METHODS}

\section{Participants}

Data are from a larger study of social problems involving 187 individuals (Fingerman \& Birditt, 2003). The sample was reduced to 184 participants due to the exclusion of three participants. An 80-year old man was excluded because he did not report any problems with his social partners and a 43-year old woman and an 84-year old man were excluded due to errors in the interview process. 
Participants included individuals ages 13 to 99 years old $(M=45.4, S D=25.7)$, representing distinct life stages: adolescents ages 13 to $16(n=39)$, young adults ages 20 to $29(n=40)$, middle-aged adults ages 40 to $49(n=33)$, young old adults ages 60 to $69(n=39)$, and oldest old adults over the age of $80(n=33)$. Prior studies of oldest old adults have rarely included younger age groups (Johnson \& Barer, 1997; Smith \& Baltes, 1997), whereas previous research in adulthood rarely includes adolescents or the oldest old (Almeida et al., 2002). Participants in the intermediate ages, such as those in their $30 \mathrm{~s}$ and $50 \mathrm{~s}$, were not included in the sample because prior studies including these ages do not demonstrate different patterns of results from adults in their 20s and 40s (Blanchard-Fields, Jahnke, \& Camp, 1995; Labouvie-Vief, Hakim-Larson, \& Hobart, 1987). Prior studies of negative experiences suggest it is more meaningful to consider variability in these experiences in terms of age categories because of the distinct experiences of individuals in different life stages (Almeida \& Horn, 2004; BlanchardFields et al., 1995).

Recruitment took place in a variety of settings, including at football games at a large university, through newspaper advertisements, community organizations, and through word of mouth. Participants received \$15 compensation for their participation. The sample consisted of predominantly Caucasian respondents (93\%). Participants included approximately equal numbers of men $(n=84)$ and women $(n=100)$ in each age group.

A $5 \times 2$ (Age group $\times$ Gender) ANOVA revealed no age or gender differences in self-rated health, with the majority of participants identifying themselves as in very good health $(M=3.9, S D=1.0)$ on a scale from 1 (poor) to 5 (excellent; Idler $\&$ Kasl, 1991). Chi-square tests estimated separately for each age group indicated a significant gender difference in marital status; all but two of the oldest old men were married, whereas all oldest old women were widowed. (For detailed information about the sample, see: Fingerman \& Birditt, 2003).

\section{Measures}

Participants completed structured interviews individually in their homes or at the study site along with written questionnaires. Measures included a demographic questionnaire and diagrams of close and problematic social networks. Then, participants described recent tensions with social network members and answered follow-up questions concerning these tensions.

\section{Background}

Participants reported their age, gender, education, religious affiliation, work status, and marital status. 


\section{Close and Problematic Relationships}

Participants completed Kahn and Antonucci's (1980) social network assessment. This questionnaire consists of three concentric circles, which represent varying degrees of psychological closeness (Antonucci \& Akiyama, 1987). Participants placed their closest relationships in the innermost circle and less close social partners in the second and third circles. This same diagram was adapted to represent degrees of irritation, with participants placing people who irritate them most in the first circle and less irritating people in the second and third circles (Fingerman \& Birditt, 2003). Participants were free to nominate the same or different social partners in their close and problematic networks.

\section{Type of Social Partner}

Participants also subjectively defined each relationship (e.g. spouse, child) they listed in the concentric circle measures. These social relationships were categorized into family (e.g. spouse, sibling, parent, and other family), friend, and acquaintance (e.g. coworker, classmate, church member). These categories have been used in previous studies of social relationships (Schuster, Kessler, \& Aseltine, 1990; Walen \& Lachman, 2000).

\section{Network Membership}

The information attained from the social network assessments was then used to classify the social partners into 3 categories: a) solely positive, b) solely problematic, and c) ambivalent (Fingerman et al., 2004). Network members who were identified in only one circle (i.e. positive or problematic) were classified as solely positive or solely negative, whereas members placed in both circles were classified as ambivalent.

\section{Types of Problems}

After completing the diagrams, participants described their most recent problematic experiences with the three closest network members and the three most problematic members. Interviewers asked participants, "Think back to a recent time when you were irritated, hurt, or annoyed with $\langle N A M E\rangle$. Can you tell me a little about what happened and why you were upset?" Participants were encouraged to describe a recent situation that had taken place within the past year. This flexible time frame offered participants the chance to describe tensions that may be emotionally salient, although these tensions may not occur daily.

Participants provided descriptions of tensions with up to six different social partners. Participants provided fewer than 6 descriptions of tensions when they: a) listed fewer than three social partners in their close or problematic networks, b) denied experiencing a problematic situation with a given network member, or c) listed the same person in both the close and problematic networks and only one 
description of tension with that partner was used in the study. Prior work with these data revealed that oldest old adults listed fewer social partners in their problematic networks than all other age group. On average, oldest old adults reported a total of four tensions with network members $(M=3.84, S D=1.38)$, whereas younger age groups reported a greater number of tensions with network members (for adolescents, $M=4.99, S D=.93$, young adults $M=5.09, S D=1.02$, middle-aged adults $M=4.93, S D=.95$, and young old adults $M=4.76$, $S D=1.07$ ). (For a more detailed discussion, see Fingerman \& Birditt, 2003).

\section{Follow-up Questions}

After describing each interpersonal tension, participants rated how upset they were (intensity of distress) on a scale ranging from 1 (not at all) to 5 (extremely). Participants also reported how long they were upset (duration of distress) following the tension they experienced with a given partner using a scale of 1 (just at the time) to 6 (upset since it happened). Finally, participants also rated the subjective importance of the tension they described on a scale ranging from 1 (not at all) to 5 (extremely).

\section{Coding of Tensions}

We classified the descriptions of tensions using a coding scheme adapted from the stressor content classification from the Daily Inventory of Stressful Experiences (DISE; Almeida et al., 2002). The DISE was originally used to code accounts of daily stressors (Mroczek \& Almeida, 2004; Neiss \& Almeida, 2004). For the purposes of this study, the content codes for interpersonal tensions were used to determine the sub-topic of tension. The DISE was originally designed for descriptions of tensions provided by adults aged 25 to 74 years. The original coding scheme consists of 21 sub-topics of interpersonal tensions.

We adapted the DISE coding scheme to the present data, which include the experiences of individuals in a wider age range (13 to 99 years). The revised scheme also included 21 sub-topics of tensions. First, a preliminary exploration of the transcripts revealed the need for the addition of 2 sub-topics (i.e., violence and religious activities) to capture the experiences of adolescents and the oldest old. One sub-topic from the original coding scheme, giving/receiving bad news, was eliminated due to its rarity in the transcripts. Finally, the sub-topic family obligations and responsibilities was conceptualized more broadly and relabeled, how target treats others; this relabeled category included tensions with the full array of social partners participants discussed.

Coders treated the sub-topics of tensions as mutually exclusive; each description was classified under only one possible sub-topic. Two independent coders received 10 hours of training to identify the sub-topics of tensions. Coders read the entire response in order to classify the response under a specific sub-topic. When a participant described multiple tensions with a given social partner, only 
the first tension was coded. Throughout the project, coders attended bi-weekly meetings to discuss disagreements and arrive at consensus. Inter-rater reliability was calculated using Cohen's kappa. Coders rated a total of 1,067 descriptions and reliability were estimated for $32 \%(n=337)$ of those descriptions. Table 1 presents examples of the sub-topic of tensions and the inter-rater reliability for these codes (kappas ranged from .66 to 1.00).

In order to examine theoretical predictions regarding the content of tensions, the 21 sub-topics of tensions were classified into 6 types of tensions developed for use with the DISE coding system (Serido, 2003). The original classifications developed by Serido included 6 types of tensions: financial issues, chores, scheduling, job, family, and self. This classification system was adapted for use in this study to examine age differences in the likelihood of experiencing various types of tensions. In this study, we kept four of the original types of tensions in their original form and modified two types of tensions. Financial issues, scheduling, family, and self were retained in their original forms. Chores was conceptualized more broadly and was renamed "daily activities" to include other types of responsibilities, and job was revised to include tensions over work and education and was renamed "job/school" due to the wider age range of individuals included in the present study. Throughout the article, these categories are referred to as "types of tension" and are used to examine age and relationship level variability in interpersonal tensions.

To determine that the sub-topics of tensions included in our coding scheme were classified into these 6 types of tensions in a theoretically appropriate manner, 20 faculty and graduate students in a human development department at a large university participated in a sorting procedure. During this procedure, these raters were instructed to sort each of the 21 sub-topics of tensions (e.g. household tasks, disrespect) into one of the 6 types of tensions (e.g. financial issues, daily tasks). Each sub-topic and its description and each of the 6 types of tension and its description were printed on separate cards. Sub-topics were considered to belong in a type of tension when the majority of expert raters (i.e. at least $50 \%$ of raters) sorted the sub-topic into the type of tension. For example, the sub-topic substance abuse was placed in the type of tension "self" by 18 of the 20 expert raters. Expert raters seemed to have the most difficulty classifying the sub-topic, religious activities, where only 8 of the 20 raters agreed that this sub-topic belonged in the type of tension labeled "self." There were also only 6 responses that fit the code for religious activities and these responses were evenly distributed across age groups. For these reasons, the sub-topic "religious activities" was dropped from analyses and not included within any type of tension.

The raters identified only one sub-topic (i.e. child discipline) as belonging in the type of tension family. This is not to say that other sub-topics do not occur with family members. For example, family members are likely to argue about household tasks or feeling disrespected, but these sub-topics were classified into the other 5 types of tensions because these issues are not unique to families and 
Table 1. Distribution of Sub-topics into Types of Tensions and Inter-rater Reliability

\begin{tabular}{|c|c|c|}
\hline Code & Example & Kappa \\
\hline \multicolumn{3}{|l|}{ Daily activities } \\
\hline Household tasks & Maintenance or cleaning of house or yard & 0.96 \\
\hline Driving/transportation & Speeding or reckless driving & 0.93 \\
\hline Recreational activities & $\begin{array}{l}\text { Club membership, sports, hobbies, and } \\
\text { social events }\end{array}$ & 0.95 \\
\hline \multicolumn{3}{|l|}{ Job/School } \\
\hline Education & $\begin{array}{l}\text { Homework, studying, grades, or disrupting } \\
\text { class, receiving detention }\end{array}$ & 0.93 \\
\hline Work-related & Too much/too little attention given to job & 0.97 \\
\hline Interactions with boss & Reporting to boss, receiving criticism & 1.00 \\
\hline Disciplining/firing & Being criticized at work or fired & 0.67 \\
\hline \multicolumn{3}{|l|}{ Scheduling } \\
\hline Timing/schedules & $\begin{array}{l}\text { Not having enough time together, } \\
\text { lateness, missed plans, arguments } \\
\text { about how to spend time }\end{array}$ & 0.96 \\
\hline \multicolumn{3}{|l|}{ Financial issues } \\
\hline Money/financial issues & Spending, saving, asking for loans & 1.00 \\
\hline \multicolumn{3}{|l|}{ Self } \\
\hline $\begin{array}{l}\text { Personal tastes \& } \\
\text { preferences }\end{array}$ & $\begin{array}{l}\text { Aesthetic tastes, personal hygiene, } \\
\text { clothing, food, or behavior in public }\end{array}$ & 0.89 \\
\hline Health/safety & $\begin{array}{l}\text { Illness, injury, medical issues, mental } \\
\text { health }\end{array}$ & 0.91 \\
\hline Possessions & $\begin{array}{l}\text { Using or damaging another person's items } \\
\text { or property }\end{array}$ & 0.94 \\
\hline Value differences & $\begin{array}{l}\text { Political, ideological, ethical, or religious } \\
\text { differences, including lying }\end{array}$ & 1.00 \\
\hline Respect/disrespect & $\begin{array}{l}\text { Decision-making, power struggles, arguing } \\
\text { about lack of respect, feeling left out or } \\
\text { ignored }\end{array}$ & 0.89 \\
\hline Miscommunication & $\begin{array}{l}\text { Unclear expectations, misunderstandings, } \\
\text { or problems with communication (e.g., } \\
\text { yelling) }\end{array}$ & 0.94 \\
\hline Violence & $\begin{array}{l}\text { Hitting, punching, kicking, or other } \\
\text { physical aggression }\end{array}$ & 0.66 \\
\hline Substance use & Drug, alcohol use or abuse & 0.91 \\
\hline General disagreement & Too vague to categorize & 0.80 \\
\hline
\end{tabular}


could occur in a range of social contexts. Because less than $3 \%$ of participants mentioned tensions classified as family and the responses were evenly distributed across age groups, this type of tension was excluded from the remaining analyses. Analyses were conducted for the remaining 5 types of tensions (i.e. financial issues, daily activities, job/school, scheduling, and self). Each type of tension was a dichotomous variable. Table 1 presents the distribution of the sub-topics into the 5 types of tensions.

\section{RESULTS}

\section{Analysis Strategy}

Age group differences in the types of tensions were examined using a multilevel modeling framework. Multilevel models were estimated separately for each of the 5 types of tensions using PROC MIXED in SAS. Multilevel modeling accounts for the hierarchical nature of the data, including unequal numbers of lower level units (i.e. social network members) nested within upper level units (i.e. study participants) (Littell, Milliken, Stroup, \& Wolfinger, 1996; Singer, 1998). In this study, the upper level unit refers to the individual level characteristic (age group), and the lower level units refer to relationship level characteristics (i.e., type of social partner and network membership) and feelings about the tension (i.e., intensity and duration of distress and importance of tension). Analyses examined whether types of tensions varied by age (upper level) and relationship level characteristics or feelings about the tension (lower level). Nonlinear multilevel models using the function for binomial outcomes were estimated because the outcome variables were dichotomous.

\section{Control Variables}

Given the established age differences in the number of tensions, the total number of tensions was controlled for in the remaining analyses. Gender was also included as a control variable in the remaining analyses because prior research indicates gender differences in negative interactions, with women reporting different problems than men (Almeida et al., 2002) and women reporting greater emotional distress in response to problems than men (Almeida \& Kessler, 1998).

\section{Age Differences in Exposure to Types of Tensions}

In general, participants most frequently described tensions involving self, followed by tensions involving scheduling, daily activities, job/school, and financial issues. Table 2 presents the average proportion of each type of tension by age group. In order to examine age group variability in the likelihood of describing the types of tensions we estimated five multilevel models: one for each type of tension (i.e., financial issues, daily activities, scheduling, job/school, and self). In all analyses, the predictor variable was age group and the control variables were gender and the total number of tensions each participant described. Although these analyses do not include lower level predictor variables (e.g., 
Table 2. Proportion of Tensions in Each Type of Tension by Age Group

\begin{tabular}{lccccc}
\hline Age Group & $\begin{array}{c}\text { Daily } \\
\text { activities }\end{array}$ & $\begin{array}{c}\text { Job/ } \\
\text { school }\end{array}$ & Scheduling & $\begin{array}{c}\text { Financial } \\
\text { issues }\end{array}$ & Self \\
\hline Adolescents & .15 & .08 & .10 & .03 & .51 \\
Young adults & .09 & .12 & .15 & .07 & .52 \\
Middle-aged adults & .13 & .12 & .13 & .09 & .43 \\
Young old adults & .06 & .08 & .16 & .09 & .46 \\
Oldest old adults & .05 & .03 & .18 & .09 & .53 \\
\hline
\end{tabular}

relationship factors), the multilevel modeling framework allowed us to account for the unequal number of tensions reported by the participants, where one participant could have described six tensions, whereas another participant could have described only four tensions.

In these analyses, we first examined age group differences by comparing each age group to the oldest old. Based on the literature, we expected oldest old adults to be most distinct in the tensions they experienced with their social partners compared to all younger age groups (Birditt \& Fingerman, 2003; Gross et al., 1997). Our results, however, indicated no differences between oldest old adults and young old adults. Therefore, in a series of post hoc analyses, we collapsed the two oldest age groups (i.e., young old and oldest old adults) into one age group. The remaining age groups (i.e., adolescent, young adults, and middle-aged adults) were each treated as distinct age groups because we were interested in how each of the younger age groups differed from adults over the age of 60. Age group was entered as three dummy coded variables where older adults (i.e., young old and oldest old) were the comparison group.

Results provided partial support for our hypotheses regarding age differences in types of tensions. As expected, there were age group differences in the likelihood of describing tensions involving job/school (Table 3). Results indicated that young adults were 2.3 times more likely to report tensions involving job/school than older adults. Contrary to our expectations, there were also age group differences in the likelihood of describing tensions over financial issues and daily activities. Adolescents were 3.3 times less likely to report tensions over financial issues than older adults. Adolescents were 2.8 times and middle-aged adults were 2.6 times more likely to describe tensions over daily activities than older adults. In contrast, there were no age group differences in tensions involving scheduling or self. Non-significant findings for scheduling and self are not tabled. 
DIFFERENCES IN TYPES OF TENSIONS / 183

Table 3. Multilevel Models Examining Type of Tension as a Function of Age Group

\begin{tabular}{|c|c|c|c|c|c|}
\hline Variables & Estimates & $S E$ & $d f$ & $t$ & Odds \\
\hline \multicolumn{6}{|l|}{ Job/school } \\
\hline Intercept & -4.29 & 0.74 & 204 & $-5.81^{\star \star \star}$ & \\
\hline Adolescents & 0.40 & 0.39 & 121 & 1.03 & 1.50 \\
\hline Young adults & 0.81 & 0.36 & 130 & $2.24 *$ & 2.26 \\
\hline Middle-aged adults & 0.68 & 0.38 & 123 & 1.78 & 1.98 \\
\hline Older adults & - & - & - & - & - \\
\hline Men & 1.07 & 0.28 & 123 & $3.86^{\star \star \star}$ & 2.90 \\
\hline Women & - & - & - & - & - \\
\hline No. of tensions & 0.21 & 0.14 & 175 & 1.56 & 1.24 \\
\hline \multicolumn{6}{|l|}{ Financial issues } \\
\hline Intercept & -2.68 & 0.69 & 293 & $-3.88^{\star \star \star}$ & \\
\hline Adolescents & -1.20 & 0.51 & 140 & $-2.33^{\star}$ & -3.31 \\
\hline Young adults & -0.60 & 0.42 & 159 & -1.42 & -1.82 \\
\hline Middle-aged adults & -0.45 & 0.42 & 148 & -1.08 & -1.57 \\
\hline Older adults & - & - & - & - & - \\
\hline Men & 0.44 & 0.32 & 165 & 1.39 & 1.55 \\
\hline Women & - & - & - & - & - \\
\hline No. of tensions & 0.05 & 0.14 & 227 & 0.34 & 1.05 \\
\hline \multicolumn{6}{|l|}{ Daily activities } \\
\hline Intercept & -3.55 & 0.75 & 232 & $-4.76^{\star * *}$ & \\
\hline Adolescents & 1.04 & 0.41 & 154 & $2.53^{\star \star}$ & 2.84 \\
\hline Young adults & 0.45 & 0.45 & 159 & 1.00 & 1.57 \\
\hline Middle-aged adults & 0.96 & 0.43 & 155 & $2.25^{\star}$ & 2.61 \\
\hline Older adults & - & - & - & - & - \\
\hline Men & 0.21 & 0.29 & 147 & 0.74 & 1.23 \\
\hline Women & - & - & - & - & - \\
\hline No. of tensions & 0.15 & 0.14 & 195 & 1.02 & 1.16 \\
\hline
\end{tabular}

${ }^{*} p<.05 ;{ }^{* *} p<.01 ;{ }^{* \star *} p<.001$.

\section{Type of Tension as a Function of Relationship Factors and Feelings about the Tension}

Next, we examined types of tensions as a function of the following relationship factors: network membership (i.e., solely positive, ambivalent, and solely negative) and type of social partner (i.e., family, friend, or acquaintance). We also examined associations between types of tensions and the following feelings about the tension: intensity of distress, duration of distress, and importance of the 
tension. First, we examined bivariate associations between relationship factors, feelings about the tension, and the 5 types of tensions to determine whether additional multilevel analyses were warranted. Bivarate results indicated job/school, scheduling, financial issues, and daily activities were significantly associated with relationship factors and feelings about the tension. Tensions involving self, however, were not significantly associated with any of the relationship factors or feelings about the tension; therefore analyses involving self were not pursued further.

Next, we examined types of tensions as a function of relationship factors and feelings about the tension using a series of multilevel models. Separate models were conducted for the remaining four types of tensions (i.e., job/school, scheduling, financial issues, and daily activities) and for each relationship factor and feeling about the tension. In all multilevel models, age group, gender, and total number of tensions were control variables, to determine whether these relationship factors and feelings about the tension were associated with types of tensions above and beyond the effects of age group, gender, and total number of tensions. In these analyses, network membership and type of social partner were dummy coded. Solely negative network member was the comparison group for network membership and acquaintance was the comparison group for type of social partner. We calculated a Bonferroni adjustment to control for Type I errors associated with conducting multiple tests. Based on this adjustment, we determined that the results needed to be significant at the $p<.003$ in order to be considered statistically significantly. Table 4 only includes the models where relationship characteristics and feelings about the tension were significantly associated with the types of tensions at the level of significance indicated by the Bonferroni adjustment. Non-significant models are not tabled.

\section{Job/school Tensions}

As expected, the likelihood of describing tensions involving job/school was significantly associated with network membership and type of social partner. Individuals were less likely to describe job/school tensions with positive network members than with negative network members and more likely to describe job/school tensions with acquaintances than with family and friends (Table 4). Feelings about the tension, including intensity and duration of distress and importance of tension, were unrelated to tensions over job/school.

\section{Scheduling}

The likelihood of reporting tensions over scheduling was associated with network membership. Participants were more likely to describe tensions over scheduling with solely positive and ambivalent network members than with solely negative network members (Table 4). The remaining relationship characteristics 
Table 4. Multilevel Models Examining Tensions as a Function of Relationship Characteristics

\begin{tabular}{|c|c|c|c|c|c|}
\hline Variables & Estimates & SE & $d f$ & $t$ & Odds \\
\hline \multicolumn{6}{|l|}{ Job/school and network membership: } \\
\hline Intercept & -3.27 & 0.81 & 266 & -4.04 & \\
\hline Adolescents & 0.43 & 0.39 & 115 & 1.09 & 1.54 \\
\hline Young adults & 0.92 & 0.37 & 126 & 2.50 & 2.51 \\
\hline Middle-aged adults & 0.72 & 0.39 & 118 & 1.86 & 2.05 \\
\hline Older adults & - & - & - & - & - \\
\hline Men & 1.05 & 0.28 & 118 & 3.80 & 2.85 \\
\hline Women & - & - & - & - & - \\
\hline Solely positive network member ${ }^{\dagger}$ & -0.88 & 0.30 & 612 & $-2.95^{\star \star}$ & -2.41 \\
\hline Ambivalent network member ${ }^{\dagger}$ & -0.87 & 0.36 & 662 & $-2.46^{\star *}$ & -2.40 \\
\hline Solely negative network member & - & - & - & - & - \\
\hline Total no. of tensions & 0.11 & 0.14 & 198 & 0.75 & 1.12 \\
\hline \multicolumn{6}{|l|}{ Job/school and type of social partner: } \\
\hline Intercept & -2.50 & 0.83 & 266 & -3.00 & \\
\hline Adolescents & 0.57 & 0.40 & 110 & 1.42 & 1.76 \\
\hline Young adults & 1.08 & 0.38 & 123 & 2.86 & 2.95 \\
\hline Middle-aged adults & 0.79 & 0.39 & 115 & 2.01 & 2.20 \\
\hline Older adults & - & - & - & - & - \\
\hline Men & 0.97 & 0.29 & 127 & 3.39 & 2.64 \\
\hline Women & - & - & - & - & - \\
\hline Family member ${ }^{\dagger}$ & -1.27 & 0.29 & 634 & $-4.39 * * *$ & -3.58 \\
\hline Friend $^{\dagger}$ & -2.45 & 0.62 & 484 & $-3.96 * * *$ & -11.60 \\
\hline Acquaintance & - & - & - & - & - \\
\hline Total no. of tensions & 0.05 & 0.14 & 185 & 0.38 & 1.06 \\
\hline \multicolumn{6}{|l|}{ Scheduling and network membership: } \\
\hline Intercept & -2.98 & 0.63 & 500 & -4.76 & \\
\hline Adolescents & -0.56 & 0.33 & 168 & -1.72 & -1.75 \\
\hline Young adults & -0.33 & 0.31 & 185 & -1.06 & -1.39 \\
\hline Middle-aged adults & -0.30 & 0.32 & 171 & -0.93 & -1.34 \\
\hline Older adults & - & - & - & - & - \\
\hline Men & -0.51 & 0.24 & 178 & -2.18 & -1.67 \\
\hline Women & - & - & - & - & - \\
\hline Solely positive network member ${ }^{\dagger}$ & 1.26 & 0.34 & 655 & $3.71^{\star \star \star *}$ & 3.51 \\
\hline Ambivalent network member ${ }^{\dagger}$ & 1.34 & 0.37 & 661 & $3.62^{* \star *}$ & 3.81 \\
\hline Solely negative network member & - & - & - & - & - \\
\hline Total no. of tensions & 0.13 & 0.11 & 284 & 1.21 & 1.14 \\
\hline \multicolumn{6}{|l|}{ Daily activities and duration of distress: } \\
\hline Intercept & -2.75 & 0.77 & 280 & -3.59 & \\
\hline Adolescents & 0.85 & 0.41 & 189 & 2.05 & 2.33 \\
\hline Young adults & 0.47 & 0.45 & 194 & 1.03 & 1.59 \\
\hline Middle-aged adults & 0.89 & 0.42 & 190 & 2.09 & 2.43 \\
\hline Older adults & - & - & - & - & - \\
\hline Men & 0.11 & 0.29 & 179 & 0.38 & 1.11 \\
\hline Women & - & - & - & - & - \\
\hline Duration of distress ${ }^{\dagger}$ & -0.30 & 0.09 & 670 & $-3.43^{* * *}$ & -1.35 \\
\hline Total no. of tensions & 0.15 & 0.14 & 229 & 1.05 & 1.16 \\
\hline
\end{tabular}

Note: ${ }^{\dagger}$ Indicates results reached the $p<.003$ statistical level indicated by the Bonferroni adjustment.

${ }^{* *} p<.01 ;{ }^{* *} p<.001$. 
and feelings about the tension were not significantly associated with tensions over scheduling.

Financial Issues

Results provided no support for our hypotheses involving tensions over financial issues. Therefore, results for financial issues are not tabled.

Daily Activities

Tensions over daily activities were associated with duration of distress. As expected, tensions over daily activities were associated with a shorter duration of distress (Table 4). In contrast, network membership, type of social partner, intensity of distress, and importance of tension were unrelated to tensions involving daily activities.

\section{DISCUSSION}

This study expands upon previous research by examining participants' descriptions of recent irritations with a variety of social partners within a wide age range, from adolescence through the oldest old. The goals of the present study were twofold: a) to examine age variability in the likelihood of experiencing different types of tensions, and b) to explore whether relationship factors and feelings about the tension were associated with different types of tensions once age was considered. Older adults were less likely to describe tensions over daily activities and job/school than younger individuals, whereas younger and older individuals were more similar in their descriptions of the other types of tensions. Further, relationship factors, particularly type of social partner and network membership, and feelings about the tension, such as duration of distress, were associated with the likelihood of describing different types of tensions. Yet, the extent to which these factors contribute to the likelihood of describing a particular tension differs across the various types of tensions.

\section{Age Differences in Exposure to Types of Tensions}

Prior research reveals robust age differences in the number of problems individuals experience with their social partners. In particular, older adults consistently report fewer problems with their network members than younger individuals (Akiyama et al., 2003; Fingerman \& Pitzer, 2006; Okun \& Keith, 1998). Yet, the specific content of these problems, specifically whether older and younger individuals are experiencing similar or different problems, has received 
less attention. Findings from this study suggest when older adults do describe tensions with their social partners; they are less likely than younger individuals to describe some types of tensions, but not others.

As expected, older individuals were less likely than young adults to report tensions about job/school. In late life individuals have completed their education and often exited the labor force, where they no longer have the chance to experience tensions involving issues over education and paid employment (Riley \& Loscocco, 1994). In contrast, young adults are actively engaged in either education or paid employment, where they are more likely to encounter tensions over education, work deadlines, work hours, or difficulties with co-workers (Robinson \& Godbey, 1997).

Contrary to our expectations, there were also age differences in the likelihood of describing tensions over financial issues and daily activities. These differences may be attributed to the social roles occupied by individuals of different ages. Specifically, results suggested adolescents were less likely to describe tensions over financial issues compared to older adults. Although adolescents argue with their parents over financial issues (Galambos \& Almeida, 1992), adolescents are still less likely to encounter tensions over finances than other age groups. Research suggests younger and older adult couples disagree over financial matters (Levenson et al., 1993; Oggins, 2003). In comparison, adolescents and middle- aged adults were more likely than older adults to describe tensions over daily activities. In adolescence, individuals often experience conflicts over everyday issues, such as household chores (Smetana, Daddis, \& Chuang, 2003), and in midlife adults report feeling overloaded by the demands of work and home that may present chances to disagree over daily activities (Almeida \& Horn, 2004). In comparison, young adults and older adults are both more likely to live alone, and this living situation may limit negative encounters with social partners over daily activities.

In contrast, other types of tensions appeared invariant with age. Chances to experience tensions over scheduling and self may be present throughout life. Despite the reduction in conflicting time demands older adults may experience (Altergott, 1990; Horgas et al., 1998; Ross, 1990) older adults were not less likely than other ages to describe tensions over scheduling. Consistent with our expectations, older and younger individuals were equally as likely to describe tensions involving the self. This finding suggests that despite age-related improvements in emotion regulation and behavioral responses to negative interactions (Birditt et al., 2005; Carstensen et al., 1999), older adults continue to experience tensions involving the nature of social interactions (i.e., self).

\section{Type of Tension as a Function of Relationship Factors and Feelings about the Tension}

Although there were age differences in reports of tensions, findings suggest that relationship factors, such as type of social partner and network membership, and 
feelings about the tension, such as duration of distress, are also associated with individuals' negative social interactions. The extent to which these factors contribute to the likelihood of experiencing various tensions, however, appears to depend on the type of tension.

Type of social partner and network membership were associated with the likelihood of describing tensions over job/school and/or scheduling, but not to the likelihood of describing other types of tensions. Not surprisingly, people were more likely to experience job/school tensions with acquaintances and less likely to experience job/school tensions with solely positive network members, whereas people were more likely to describe tensions over scheduling with solely positive and ambivalent network members. These results provide support for the finding that when individuals have frequent contact with a social partner, they are likely to experience tensions with that person (Akiyama et al., 2003). Further, positive and ambivalent ties are generally more emotionally salient relationships than negative ties (Fingerman et al., 2004). This closeness may increase the likelihood of experiencing tensions over timing because individuals may be invested in how network members are spending time, such that how close network members choose to spend their time may be a source of interpersonal tension. In contrast, these issues may be less likely to arise with solely negative network members because participants may not care as much about how these members use their time.

Duration of distress was also associated with types of tensions. Consistent with our expectations, tensions over daily activities were associated with short-lived distress. These tensions may be associated with short-lived distress because they are unlikely to endanger something of personal value, such as monetary resources (Almeida et al., 2002; Lazarus, 1999). This finding supports the expectation that attributes of a situation, such as the type of tension, may be associated with how individuals emotionally respond to a situation (Birditt \& Fingerman, 2003; Serido, 2003). Unexpectedly, intensity and duration of distress were not associated with tensions over job/school or self.

It was also somewhat surprising that the subjective importance of the tension was not associated with any of the types of tensions. One possible explanation for this finding could be related to the time frame, where participants were free to describe tensions that had occurred within the last year. This open-ended time frame may have led participants to describe tensions that had occurred in the past. Tensions may be evaluated as less important after time has passed compared to when they first occurred (Almeida, 2005). This time lag may in part explain why there were no associations between the types of tensions and the rated importance of those tensions.

It is important to note that tensions involving self were unrelated to characteristics of the relationship or feelings about the tension. The lack of associations between self tensions, feelings about the tension, and relationship factors may be explained in part by the constellation of sub-topics grouped within this type of 
tension. Disagreements over feeling disrespected or miscommunications may arise with different social partners and may be associated with different levels of emotional distress than tensions over sharing possessions or value differences. Yet, based on our classification system, all of these sub-topics fell under the same type of tension. Although this classification was based on the recommendation of expert raters, it is possible that collapsing these various sub-topics into one type of tension limited our ability to find associations between relationship factors, feelings about the tension, and tensions over self.

\section{Limitations and Directions for Future Research}

An additional limitation of the current study is the cross-sectional design. This design makes it possible to examine age differences in types of tensions. Only longitudinal data, however, would allow us to examine how age-related changes (i.e., retirement) contribute to changes in the likelihood of experiencing tensions. It is also necessary to acknowledge that with our cross-sectional data we cannot be sure of the direction of our effects. Tensions involving scheduling could contribute to more ambivalent relationships rather than more ambivalent relationships leading to a greater likelihood of experiencing tensions over scheduling.

Further, the selection of tensions may hold implications for age variability in types of tensions. For example, excluding tensions involving family or the topic religious activities could have minimized the opportunity to identify areas in which older adults may be more likely to experience tension. In this study, however, tensions involving family were excluded because only one sub-topic that made up less than $3 \%$ of the responses was classified within this category and these responses were evenly distributed across age groups. Similarly, few responses fit the sub-topic religious activities and these responses were also distributed across the age groups. Future studies should consider examining age differences in tensions involving family and religious activities in larger samples that also encompass a wider range of family-related tensions.

Other limitations include the homogeneity of the sample. It is unclear whether we would obtain similar findings in more ethnically or socioeconomically diverse samples. For example, age differences in the likelihood of describing tensions regarding job/school may be more pronounced in a sample with fewer economic resources, where older adults may be more limited in their opportunities to exit the labor force (Han \& Moen, 1999).

The mutually exclusive nature of the coding scheme may also be a limitation, in the sense that it forced descriptions to be classified into only one type of tension, when in reality a single description of an interpersonal tension could encompass several different issues. For example, an argument over household tasks could also 
be about feeling disrespected. Future research should examine the depth of negative interactions by examining multi-dimensional sources of tensions.

\section{CONCLUSIONS}

Despite these limitations, the present study contributes to the body of literature on negative interactions in several ways. Findings from this study provide information on the tensions experienced by individuals within a wide age range from adolescence through late-late life. In particular, this study compares the experiences of older adults to those of younger individuals and finds that although differences exist in the likelihood of experiencing some types of tensions (i.e. job/school, financial issues, and daily activities), age similarity characterizes other types of tensions. This study also expands on prior research by considering relationship factors and feelings about tension, such as type of social partner or the duration of distress in response to interpersonal tensions that may be associated with variability in the likelihood of experiencing types of tensions. Overall, findings suggest various relationship factors and feelings about the tension, beyond the effects of age, are associated with the likelihood of experiencing different types of tensions.

\section{REFERENCES}

Akiyama, H., Antonucci, T., Takahashi, K., \& Langfahl, E. S. (2003). Negative interactions in close relationships across the life span. Journal of Gerontology: Psychological Sciences, 58B, P70-P79.

Almeida, D. M. (2005). Resilience and vulnerability to daily stressors assessed via diary methods. Current Directions in Psychological Science, 14(2), 64-68.

Almeida, D. M., \& Horn, M. C. (2004). Is daily life more stressful during middle adulthood? In O. G. Brim, C. D. Ryff, \& R. C. Kessler (Eds.), How healthy are we? A national study of well-being at midlife (pp 425-451). Chicago: The University of Chicago Press.

Almeida, D. M., \& Kessler, R. C. (1998). Everyday stressors and gender differences in daily stress. Journal of Personality and Social Psychology, 75, 670-680.

Almeida, D. M., Wethington, E., \& Kessler, R. C. (2002). The daily inventory of stressful experiences (DISE): An interview-based approach for measuring daily stressors. Psychological Assessment, 19, 41-55.

Altergott, K. (1990). Age, gender, and daily life: An analysis of social involvements. Social Indicators Research, 23, 367-380.

Antonucci, T. C., \& Akiyama, H. (1987). Social networks in adult life and a preliminary examination of the convoy model. Journal of Gerontology, 42, 519-527.

Birditt, K. S., \& Fingerman, K. L. (2003). Age and gender differences in adults' descriptions of emotional reactions to interpersonal problems. Journal of Gerontology: Psychological Sciences, 58B. P237-P245. 
Birditt, K. S., Fingerman, K. L., \& Almeida, D. M. (2005). Age differences in exposure and reactions to interpersonal tensions: A daily diary study. Psychology and Aging, 20, 330-340.

Blanchard-Fields, F., Jahnke, H. C., \& Camp, C. (1995). Age differences in problemsolving style: The role of emotional salience. Psychology and Aging, 54, 165-181.

Blieszner, R., \& Adams, R. G. (1998). Problems with friends in old age. Journal of Aging Studies, 12, 223-238.

Bolger, N., DeLongis, A., Kessler, R. C., \& Schilling, E. A. (1989). Effects of daily stress on negative mood. Journal of Personality and Social Psychology, 37, 808-818.

Carstensen, L. L., Issacowitz, D. M., \& Charles, S. T. (1999). Taking time seriously: A theory of socioemotional selectivity. American Psychologist, 54, 165-181.

Clarke, E. J., Preston, M., Raksin, J., \& Bengston, V. L. (1999). Types of conflict and tensions between older parents and their adult children. The Gerontologist, 39(2), 261-270.

Fingerman, K. L. (1996). Sources of tension in the aging mother and adult daughter relationship. Psychology and Aging, 11, 591-606.

Fingerman, K. L., \& Birditt, K. S. (2003). Do age differences in close and problematic family ties reflect the pool of available relatives? Journal of Gerontology: Psychological Sciences, 58B, P80-P87.

Fingerman, K. L., Hay, E. L., \& Birditt, K. S. (2004). The best of ties, the worst of ties: Close, problematic, and ambivalent relationships across the lifespan. Journal of Marriage and Family, 66, 792-808.

Fingerman, K. L., \& Pitzer, L. M. (2006). Socialization in old age. To appear in P. D. Hastings \& J. E. Grusec (Eds.), Handbook of Socialization (pp. 232-255). New York: Guilford Press.

Galambos, N. L. \& Almeida, D. M. (1992). Does parent-adolescent conflict increase in early adolescence? Journal of Marriage and the Family, 54, 737-747.

Gross, J. J., Carstensen, L. L., Pasupathi, M., Tsai, J., Skorpen, C. G., \& Hsu, A. Y. C. (1997). Emotion and aging: Experience, expression, and control. Psychology and Aging, 12, 590-599.

Han, S., \& Moen, P. (1999). Clocking out: Temporal patterning of retirement. American Journal of Sociology, 105, 191-236.

Herzog, A. R., Kahn, R. L., Morgan, J. N., Jackson, J. S., \& Antonucci, T. C. (1989). Age differences in productive activities. Journal of Gerontology: Social Sciences, 44, S129-S138.

Horgas, A. L., Wilms, H., \& Baltes, M. M. (1998). Daily life in very old age: Everyday activities as expression of successful living. The Gerontologist, 38, 556-568.

Idler, E. L., \& Kasl, S. (1991). Health perceptions and survival: Do global evaluations of healthy status really predict mortality? Journals of Gerontology: Social Sciences, 46, S55-S65.

Johnson, C. L., \& Barer, B. M. (1997). Life beyond 85 years: The aura of survivorship. New York: Springer.

Kahn, R. L., \& Antonucci, T. C. (1980). Convoys over the life course: Attachment, roles, and social support. Life-Span Development and Behavior, 3, 253-386. 
Labouvie-Vief, G., Hakim-Larson, J., \& Hobart, C. J. (1987). Age, ego level, and life-span development of coping and defense processes. Psychology and Aging, 2, 286-294.

Lazarus, R. S. (1999). Stress and Emotion: A New Synthesis. New York: Springer.

Levenson, R. W., Carstensen, L. L., \& Gottman, J. M. (1993). Long-term marriage: Age, gender, and satisfaction. Psychology and Aging, 8, 301-313.

Littell, R. C., Milliken, G. A., Stroup, W. W., \& Wolfinger, R. D. (1996). SAS system for mixed models. North Carolina: SAS Institute Inc.

Michelson, W. (1990). Childcare and the daily routine. Social Indicators Research, 23, 353-366.

Mroczek, D. K., \& Almeida, D. M. (2004). The effect of daily stress, personality, and age on daily negative affect. Journal of Personality, 72, 355-378.

Neiss, M., \& Almeida, D. M. (2004). Age differences in the heritability of mean and intraindividual variation of psychological distress. Gerontology, 50, 22-27.

Oggins, J. (2003). Topics of marital disagreement among African American and EuroAmerican newlyweds. Psychological Reports, 92, 419-425.

Okun, M. A., \& Keith, V. M. (1998). Effects of positive and negative social exchanges with various sources on depressive symptoms in younger and older adults. Journal of Gerontology: Psychological Sciences, 53B, P4-P20.

Raffaelli, M. (1997). Young adolescents' conflicts with siblings and friends. Journal of Youth and Adolescence, 2, 539-558.

Riley, M. W., \& Loscocco, K. A. (1994). The changing structure of work opportunities: Toward an age-integrated society. In R. P. Abeles, H. C. Gift, \& M. G. Ory (Eds.), Aging and Quality of Life (pp. 235-252). New York: Springer.

Robinson, J. P., \& Godbey, G. (1997). Time for life: The surprising ways Americans use their time. University Park, PA: The Pennsylvania State University Press.

Rook, K. S. (2003). Exposure and reactivity to negative social exchanges: A preliminary investigation using daily diary data. Journal of Gerontology: Psychological Sciences, $58 B, \mathrm{P} 100-\mathrm{P} 111$.

Ross, M. M. (1990). Time-use in later life. Journal of Advanced Nursing, 15, 394-399.

Schuster, T. L., Kessler, R. C., \& Aseltine, R. H. (1990). Supportive interactions, negative interactions, and depressed mood. American Journal of Community Psychology, 18, 423-438.

Serido, J. (2003). Appraisal and interpersonal stressors: Untangling the stress process. (Doctoral dissertation, University of Arizona, 2003). Dissertation Abstracts International, 64, 5257.

Singer, J. D. (1998). Using SAS PROC MIXED to fit multilevel models, hierarchical models, and individual growth models. Journal of Educational \& Behavioral Statistics, 23, 323-355.

Smetana, J. G., Daddis, C., \& Chuang, S. S. (2003). “Clean your room!”: A longitudinal investigation of adolescent-parent conflict and conflict resolution in middle-class African American families. Journal of Adolescent Research, 18, 631-650.

Smith, J., \& Baltes, P. B. (1997). Profiles of psychological functioning in the old and the oldest old. Psychology and Aging, 12, 458-472.

Suitor, J. J. (1991). Marital quality and satisfaction with the division of household labor across the family life cycle. Journal of Marriage and the Family, 53, 221-230.

Troll, L. (1988). New thoughts on old families, The Gerontologist, 28, 586-591. 
Uchino, B. N., Holt-Lunstad, J., Uno, D., \& Flinders, J. B. (2001). Heterogeneity in the social networks of young and older adults: Prediction of mental health and cardiovascular reactivity during acute stress. Journal of Behavioral Medicine, 24, 361-382.

Walen, H. R., \& Lachman, M. E. (2000). Social support and strain from partner, family, and friends: Costs and benefits for men and women in adulthood. Journal of Social and Personal Relationships, 17, 5-30.

Wilkie, J. R., Ferree, M. M., \& Ratcliff, K. S. (1998). Gender and fairness: Marital satisfaction in two-earner couples. Journal of Marriage and the Family, 60, 577-594.

Direct reprint requests to:

Kelly E. Cichy

Department of Human Development

and Family Studies

Pennsylvania State University

University Park, PA 16802

e-mail: Kec184@psu.edu 